\title{
ВОЗМОЖНОЕ Я: ПОДХОД ХЕЙЗЕЛ МАРКУС
}

\section{В.Ю. КОСТЕНКО}

${ }^{a}$ Национальный исследовательский университет «Высшая школа экономики», 101000, Россия, Москва, ул. Мясницкая, д. 20

\section{Резюме}

В статье приводится развернутый обзор и анализ ключевых публикаций по теории возможного Я. Обобщаются имеющиеся в рамках данного подхода теоретические представления, раскрывается исследовательский потенциал подхода, представляются пути его практического применения. Автор понятия, Хейзел Маркус, вводит новый компонент возможного Я в общую структуру Я-концепции для объяснения влияния на образ Я потенциальных представлений о себе. Возможное Я - это направленный в сферу будущего и возможного компонент Я-концепции, являющийся когнитивным выражением ожиданий, целей, страхов, надежд, стремлений субъекта и выступающий как связующее звено между когнитивной оценкой себя и мотивацией. Текущая оценка человеком самого себя, в понимании Х. Маркус, учитывает возможные Я, которыми человек хотел бы стать, Я, которых он избегает, и даже Я, которые никогда не станут реальностью. При этом данный механизм не сводится лишь к осознанию цели или оценке возможного будущего, но обязательно включает переживание потенциальной ситуации изнутри и оценку возможностей действовать тем или иным образом. В такой форме он становится важным инструментом развития личности, личностным ресурсом совладания с трудностями и саморегуляции деятельности. Анализируются роль и место данного подхода в общей теории Я-концепции. Раскрываются понятия «Я-схема» и «рабочая Я-концепция». Раскрываются некоторые возможности применения данного подхода в психотерапии. Приводятся результаты ряда эмпирических исследований, выполненных в рамках данного подхода. Показано, что конструкт возможного Я проявляет высокий эвристический потенциал и демонстрирует широкие возможности применения в психологической практике.

Ключевые слова: возможное Я, Я-концепция, самодетерминация, саморегуляция, личностные ресурсы. 
За более чем трехсотлетнюю историю развития представлений о Я в рамках философии и психологии данный конструкт постепенно обособлялся от базовых понятий о душе, сознании, личности, оформляясь в самостоятельную категорию. В психологии $\mathrm{XX}$ в. ситуация усложнилась в связи с введением новых понятий, пропитанных удивительно близким содержанием: Эго, Самость, личность, Я-концепция и др., часто призванные составить ядро новой теории, создали ситуацию, в которой трудно будет разобраться и целой команде историков. Для новейших исследований в этой области характерны, по меньшей мере, две тенденции.

Первая тенденция связана с новой волной интереса к проблеме Я. Так, за последние 30 лет множество новых трактовок данной категории появились в рамках нейропсихологии, теории самодетерминации, экзистенциального подхода, теории Я-концепции, а также в прикладной психотерапевтической области. Актуальная терминология Я включает десятки предикатов к нему, среди которых диалогическое Я (Губерт Херманс), расколотое Я (Рональд Лэнг), пресыщенное Я (Кеннет Герген), мнимое Я (В.А. Петровский), феноменальное Я (В.В. Столин) и мн. др.

Вторая тенденция касается привлечения в эту область нового теоретического материала - теории хаоса и нелинейных динамических систем, афтер-постмодернистских философских концепций, некаузальных объяснительных моделей и т.п. Широкое использование метафор в описании понятия и подчеркивание парадоксальности Я соседствуют с попытками применить принципы новых естественно-научных достижений при построении теоретических моделей его функционирования.

Синтезом этих идей выступает конструкт так называемого возможного Я. В психологической науке «возможное» зачастую противопоставлено «детерминированному» и «реактивному», дополняя таким образом модальности «действительного» и «необходимого» (Эпштейн, 2001). В центре внимания в таком случае оказываются феномены психики, которые либо недетерминированы, либо самодетерминированы (Леонтьев, 2011a). Опираясь на философскую категорию «возможного», Хейзел Маркус открывает новый горизонт в исследованиях этой области, и в данной статье мы остановимся на ключевых идеях данного подхода. Подход Х. Маркус не единственный пример такого синтеза, некоторые российские авторы развивают сходные идеи. Среди них Д.А. Леонтьев (2014), В.А. Петровский (2014), А.Ш. Тхостов (1994), Л.Я. Дорфман (2004) и др. Однако в нашей работе речь пойдет, в первую очередь, о зарубежном опыте разработки исследуемой проблемы. Дефицит русскоязычных публикаций, раскрывающих сущность подхода Х. Маркус и ее последователей, восполнен в данной работе внимательным изучением термина в непростом теоретическом контексте. Проблематика возможного Я является дискуссионной, обладает высоким теоретическим потенциалом, а также открывает новые пути для решения научно-практических задач. Нам 
представляется важным обобщить имеющиеся в рамках данного подхода теоретические представления, раскрыть эвристический потенциал понятия и представить пути его практического применения.

\section{Конструкт возможного Я в контексте общей теории Я- концепции}

Трудно спорить с тем, что наиболее успешная попытка операционализировать конструкт Я и приблизиться к его эмпирическому изучению была предпринята именно в рамках теории Я-концепции. Как следует из названия подхода, ядро теории составляет понятие Я-концепции, или образа Я (self-concept, self-construct, self-identity). Согласно определению словаря Американской психологической ассоциации, «Я-концепция это описание и оценка человеком самого себя, включающая психологические и физические характеристики, качества и способности» (American Psychological Association, 2015, р. 953). Образ Я составлен из относительно стабильных и доступных осознанию самоописаний и образует целостный работоспособный комплекс, устойчивый к изменениям как внешней среды, так и внутренних состояний индивида. Не вся Я-концепция, однако, постоянно осознана индивидом, но только та ее часть, которая необходима в рамках текущей активности. Таким образом, в качестве содержания Яконцепции могут выступать личностные черты («я целеустремленный», «я женственная»), физические особенности тела («я среднего роста», «я голубоглазый»), социальные роли («я дизайнер», «я мать», «я либеральных взглядов»), навыки и способности («я хорошо управляю автомобилем», «я быстро читаю») и подобные им характеристики. В то же время в нее не включаются описания вре́менных состояний («мне тепло», «я спокоен»), текущей деятельности («я бегу»), положения в пространстве («я в метро») и подобные им.

В то время как большинство исследований Я-концепции сфокусированы на устойчивом и фактическом ее содержании, подход Хейзел Маркус демонстрирует: наличное знание о себе находится под существенным влиянием потенциальных представлений о себе. Для объяснения такого влияния в Я-концепцию вводится компонент возможного Я.

Возможное Я - это направленный в сферу будущего и возможного компонент Я-концепции, являющийся когнитивным выражением ожиданий, целей, страхов, надежд, стремлений субъекта и выступающий как связующее звено между когнитивной оценкой себя и мотивацией. Спектр возможных Я, в определении автора, объединяет в себе «Я, которыми мы очень хотели бы стать... Я, которыми мы могли бы стать, и Я, которыми мы стать боимся» (Markus, Nurius, 1986, p. 954). Черпая свое содержание из прошлого (как того, что было возможно) и воображаемого будущего (желаемого и избегаемого), возможные Я создают побудительный и аффективный контекст для актуального ви́дения себя. В то же время, отражая мотивацию деятельности, они функционируют как фильтр будущего поведения и задают поле действия мотива. 


\section{Конструкт возможного Я в теории X. Маркус и ее последователей}

Статья Хейзел Маркус, в которой был впервые введен интересующий нас термин, увидела свет в 1986 г. Согласно данным SCOPUS®, к середине 2016 г. она была процитирована более чем в 2300 рецензируемых источниках. Термин «possible self», по данным PsycINFO®, релевантен более чем 300 академическим работам по психологии, из которых больше половины - эмпирические исследования. Тематика прикладных работ, использующих данный концепт, крайне широка и охватывает гендерные различия, кросс-культурные особенности, академические достижения, делинквентное поведение и мн. др. Теоретические исследования по данной теме разворачиваются как в первоначальном русле когнитивных теорий, так и в рамках теории саморегуляции, нарративной психологии и ряда других подходов. В последние десять лет интерес к данному концепту неуклонно растет. Чем же являются и чем не являются возможные Я, какие формы они принимают и как взаимодействуют с другими компонентами образа Я?

Возможные Я различаются у Маркус по двум основаниям. Прежде всего, в зависимости от возникающего у индивида отношения, среди них существуют желательные (позитивные) и нежелательные Я (избегаемые, негативные). В разработанной Маркус и Ньюриус методике, содержащей 150 различных вариантов возможных Я, выделяется шесть содержательных групп. В первую группу попадают категории, описы- вающие черты характера, такие как быть креативным, находчивым, эгоистичным. Этот набор черт является типичным для опросников, исследующих Я-концепцию. Вторая группа характеризует телесные особенности - быть привлекательным, атлетичным, морщинистым, слепым и др. Третья группа описывает возможные Я, относящиеся к образу жизни. Среди них быть активным в общественной жизни, быть психически здоровым, алкогольно зависимым, неизлечимо больным. Четвертый блок посвящен различным способностям - хорошо готовить, чинить вещи, влиять на людей, разбираться в музыке. Пятая группа описывает различные профессиональные возможности - быть бизнесменом, судьей верховного суда, водителем такси, офицером полиции. Последний блок связан с отношением к индивиду других людей - быть уважаемым, любимым, изгоем (Markus, Nurius, 1986, p. 958). Помимо содержания, для эмпирических исследований характерно использование в качестве критерия оценки возможных Я субъективной вероятности их воплощения в жизнь.

Для понимания особой роли возможного Я следует воспользоваться оригинальной теорией Маркус и проследить связь данного понятия с двумя другими компонентами образа Я - Я-схемы и рабочей Я-концепции.

Я-cхема (self-schema) - это компонент Я-концепции, ответственный за организацию и трансляцию информации о себе, необходимой для текущей деятельности. «Индивид, обладающий “Я-схемой” в определенной сфере активности... использует 
свои “Я-схемы” для вынесения быстрых и уверенных суждений, для гибкой адаптации к различным задачам обработки информации и для точного извлечения информации, релевантной этой сфере активности» (Cross, Markus, 1994, p. 423). Стоит отметить, что Я-схемы не заключают в себе саму способность действовать и не являются диспозицией к действию, а лишь отражают индивидуальный характер отбора и оценки информации о себе, необходимой для данной активности. Именно наличие или отсутствие Я-схем, релевантных конкретному возможному Я, определяет степень его реалистичности. Так, возможное Я «быть в скором будущем водителем личного автомобиля» будет полнее и реалистичнее для человека, обладающего навыками вождения, чем для человека, никогда не садившегося за руль.

Другая категория, необходимая для понимания функционирования возможного Я в общей когнитивной структуре, - рабочая Я-концепция (working self-concept). Она охватывает часть текущего содержания сознания и «может быть рассмотрена как непрерывно активное, изменяющееся множество доступного знания о себе» (Markus, Nurius, 1986, p. 957). Рабочая Я-концепция находится под непрерывным влиянием прошлого содержания образа Я, наличной ситуации и требований текущей активности. Возможное Я и рабочая Я-концепция обмениваются информацией и формируют друг друга. К примеру, после подачи документов абитуриент может переживать нежелательное возможное Я «быть абитуриентом, провалившим экзамены», что, несомненно, окажет влияние на его оценку себя и фактическое поведение в период экзаменов. С другой стороны, существовавшее до экзаменов возможное Я «быть студентом МГУ» совершенно изменится с первых дней учебы, после того как актуальная оценка себя и новая поступающая информация окажут свое влияние.

Существует опасность слишком узкого понимания описываемого конструкта - как идеального Я или, напротив, слишком широкой интерпретации как отражения любой цели, намерения, угрозы в форме когнитивных репрезентаций.

В первую очередь, возможное Я следует отличать от идеального Я, природа возникновения которого совершенно иная. Идеальное Я задается социальными нормативами и включает в себя в основном положительные характеристики (кем я должен быть), в то время как возможное Я является отражением собственной мотивации индивида и может предполагать как положительное, так и отрицательное отношение к его содержанию (Белинская, 1999).

Было отмечено, что возможное Я может являться когнитивным отражением как ожиданий и надежд, так и страхов, опасений индивида. Мартин Эриксон внес ряд существенных разъяснений этого положения. Так, содержание возможного Я никогда не ограничивается лишь оценкой будущего как желаемого или избегаемого. Оно необходимо включает «переживание этой ситуации “изнутри”» (Erikson, 2007, р. 349). Возможное Я - это всегда возможность быть так или иначе, субъективный опыт присутствия в потенциальной 
жизненной ситуации. Кроме того, конструирование возможного Я отличается от простой постановки цели или осознания некоторой угрозы: возможное Я предполагает переживание себя в качестве субъекта активности, а значит, включает субъективный опыт возможности действовать тем или иным образом из новой потенциальной точки. Например, желание человека найти хорошую работу будет являться возможным Я только тогда, когда он представит, каково ему будет и как он сможет действовать в роли человека, у которого есть хорошая работа. Но такого переживания и возможного Я может и не возникнуть в случае, если цель - приготовить ужин и нет никакой необходимости переживать себя «ужинающим». С другой стороны, в качестве возможного Я может выступать воображаемое путешествие на Северный полюс безотносительно к желанию воплотить это в жизнь; или возможность приобрести неизлечимое заболевание, даже если для такой фантазии нет никаких оснований. Отсюда следует, что не все опасения и надежды воплощаются в возможных Я и не всякое возможное Я является отражением направленности личности. Однако в своей повседневной функции они призваны отражать наиболее вероятную возможность, и именно в этом качестве чаще всего становятся предметом эмпирических исследований.

Таким образом, возможное Я это не некоторое стабильное образование, но всегда опыт, переживание; не факт и не результат оценки, но субъективное пространство потенииальной активности субъекта (agenсу) - как желаемой, так и избегаемой.
Возможное Я можно рассматривать и как инстанцию, в которой заключена потенция к изменению и развитию. По мнению Маркус, «через отбор и конструирование возможных Я человек предстает в качестве активного созидателя своего собственного развития» (Markus, Nurius, 1986, p. 955). Действительно, ситуация выбора возможного себя качественно отлична от ситуации выбора любой другой возможности. Как выбор из возможностей субъектности он определяет прочие возможности действовать. Это выбор быть тем или иным источником активности, конструирование того или иного способа быть.

\section{Возможное Я в эмпирических исследованиях и психотерапии}

Хотя возможное Я по своей природе легко поддается самоотчету, его влияние на личность выходит за рамки простого самоопределения, распространяясь на последующую деятельность. Показано, что в переживании возможного Я неизбежно возникает и эмоциональное отношение к нему, в свою очередь, оказывающее влияние на силу мотивации: «осознание желаемого возможного Я может стимулировать возникновение позитивного эмоционального состояния, и желание сохранить или усилить это состояние является побудительным или дающим силы» (Cross, Markus, 1994, p. 424).

Сила мотива будет зависеть и от соотношения желаемых и избегаемых возможных Я, возникающих вокруг одной потребности. Наибольшую побудительную силу будет иметь сбалансированное соотношение, при 
котором имеются как возможные Я достижения желаемого, так и возможные Я избегания неудачи в удовлетворении потребности. Такая ситуация не только увеличивает совокупную силу мотива, но и «расширяет репертуар поведения, релевантного желаемому результату» (Hoyle, Sherrill, 2006, p. 1678). Напротив, «недостаток таких побудительных качеств может быть связан с существованием хорошо проработанных негативных возможных Я, которые дают яркую когнитивную форму индивидуальным страхам и опасностям, но не содержат стратегий, или Я-сценариев, о том, как избежать их» (Markus, Nurius, 1986, p. 962). Показано, что с возрастом личность достигает все большего соответствия желаемого и действительного представления о себе, изменяются содержание и роль возможных Я (Ryff, 1991).

Прикладное значение теории Маркус проявило себя в консультативной психологии. Так, например, из делинквентных исследований вытекает важное для терапевтической практики следствие: самооценка и уровень притязаний не столько определяют реальное поведение, сколько представление о себе в будущем (Oyserman, Markus, 1990). Моделирование возможных Я, поддерживающих позитивные изменения, - одно из направлений работы в рамках терапевтической сессии (Dunkel et al., 2006). В то же время на материале исследований академической и карьерной успешности показано, что ригидность возможных Я может выступать в качестве серьезного препятствия для достижения поставленных целей, а их переработка и изменение, напротив, способствуют успешной адаптации в новых условиях (Pizzolato, 2007). Возможные Я, таким образом, могут быть рассмотрены и как один из ресурсов устойчивости личности и совладания с трудностями.

Метафора Я или Эго как гироскопа, часто упоминаемая в литературе (см., например: Кон, 1984, с. 141; Леонтьев, 2011б, с. 59; Bolkan, Hooker, 2012, p. 357), находит свое развернутое теоретическое обоснование и в подходе X. Маркус: кажущаяся стабильность фактических поведенческих проявлений сопровождается мириадами незаметных глазу наблюдателя оценок и переживаний возможного состояния Я. Последние, согласуясь с относительно стабильными условиями действительности, оказывают микро- и макровлияние на «изменение курса» деятельности. Конструкт возможного Я, таким образом, проявляет высокий эвристический потенциал для психологии личности и демонстрирует широкие возможности применения в психологической практике.

\section{Литература}

Белинская, Е. П. (1999). Временные аспекты Я-концепции и идентичности. Мир психологии, 3 , 40-46.

Дорфман, Л. Я. (2004). Я-концепция: Дифференциация и интеграция. В кн. Л. Я. Дорфман (ред.), Интегральная индивидуальность, Я-концепция, личность (с. 96-123). М.: Смысл. 
Кон, И. С. (1984). В поисках себя: Личность и ее самосознание. М.: Политиздат.

Леонтьев, Д. А. (2011а). Новые ориентиры понимания личности в психологии: От необходимого к возможному. Вопросы психологии, 1, 3-27.

Леонтьев, Д. А. (2011б). Подход через развитие эго: Уровневая теория Дж. Лёвинджер. В кн. Д. А. Леонтьев (ред.), Личностный потенциал: Структура и диагностика (с. 59-78). М.: Смысл.

Леонтьев, Д. А. (2014). Конец имманентности и перспектива возможного. В кн. Г. Л. Белкина (ред.), Место и роль гуманизма в будущей цивилизации (с. 174-185). М.: Ленанд.

Петровский, В. А. (2014). Я: Конфигурации артефакта. Культурно-историческая психология, 10(1), 63-78.

Тхостов, А. Ш. (1994). Топология субъекта (Опыт феноменологического исследования). Вестник Московского университета. Серия 14. Психология, 2, 3-13.

Эпштейн, М. Н. (2001). Философия возможного: Модальности в мышлении и культуре. СПб.: Алетейя.

American Psychological Association. (2015). APA dictionary of psychology. Washington, DC: American Psychological Association.

Bolkan, C., \& Hooker, K. (2012). Self-regulation and social cognition in adulthood: The gyroscope of personality. In S. K. Whitbourne \& M. J. Sliwinski (Eds.), The Wiley-Blackwell handbook of adulthood and aging (pp. 357-380). West Sussex: Blackwell Publishing Ltd.

Cross, S., \& Markus, H. (1994). Self-schemas, possible selves, and competent performance. Journal of Educational Psychology, 86(3), 423-438. doi:10.1037/0022-0663.86.3.423

Dunkel, C., Kelts, D., \& Coon, B. (2006). Possible selves as mechanisms of change in therapy. In C. Dunkel \& J. Kerpelman (Eds.), Possible selves: theory, research and application (pp. 187-204). New York: Nova Science Publishers Inc.

Erikson, M. (2007). The meaning of the future: Toward a more specific definition of possible selves. Review of General Psychology, 11(4), 348-358. doi:10.1037/1089-2680.11.4.348

Hoyle, R., \& Sherrill, M. (2006). Future orientation in the self-system: Possible selves, self-regulation, and behavior. Journal of Personality: Journal Compilation, 74(6), 1673-1696.

Markus, H., \& Nurius, P. (1986). Possible selves. American Psychologist, 41(9), 954-969. doi:10.1037/0003-066X.41.9.954

Oyserman, D., \& Markus, H. (1990). Possible selves and delinquency. Journal of Personality and Social Psychology, 59(1), 112-125.

Pizzolato, J. E. (2007). Impossible selves: Investigating students' persistence decisions when their career-possible selves border on impossible. Journal of Career Development, 33(3), 201-223. doi:10.1177/0894845306296644

Ryff, C. D. (1991). Possible selves in adulthood and old age: A tale of shifting horizons. Psychology and Aging, 6(2), 286-295. doi:10.1037/0882-7974.6.2.286

Костенко Василий Юрьевич - младший научный сотрудник, Международная лаборатория позитивной психологии личности и мотивации, Национальный исследовательский университет «Высшая школа экономики».

Контакты: vasily.kostenko@gmail.com 


\title{
Possible Self: Theory by Hazel Markus
}

\author{
Vasiliy Yu. Kostenko ${ }^{a}$ \\ ${ }^{a}$ National Research University Higher School of Economics, 20 Myasnitskaya str., Moscow, 101000, \\ Russian Federation
}

\begin{abstract}
The article is dedicated to the review and analysis of the key publications on the "Possible self" theory. The theoretical representations developed within this approach are provided in the text. The research potential of the approach is elaborated, and ways of its practical application are represented. Hazel Markus, the author of the term "possible self", adds a new component to the general model ofself-concept for an explanation of how concepts of potency influence selfconcept as a whole. Possible self is the part of self-concept that appeals to the sphere of future and potency, and serves as a cognitive expression of expectations, goals, fears, hopes and aspirations of the subject, as well as the link between cognitive appraisal of self and motivation. The current estimation of the self, as H. Markus believes, considers possible selves, those that the person would like to become, selves that he avoids, and even selves that will never become real. At the same time this mechanism is not reduced only to understanding of the goal or appraisal of the possible future, but surely includes experience of a potential situation from within and appraisal of opportunities to act. In such form it becomes the important instrument of the personality development and personality resource of self-regulation and coping with difficulties. The role and the place of this approach in the general theory of self-concept were analyzed. The concepts "self-schema" and "working self-concept" were defined. Some opportunities of application of this approach in psychotherapy are revealed. Results of some empirical studies provided within this approach are given. It is shown that possible self construct demonstrates high heuristic potential and demonstrates ample opportunities of application in psychological practice.
\end{abstract}

Keywords: possible self, self-concept, self-determination, personality resources.

\section{References}

American Psychological Association. (2015). APA dictionary of psychology. Washington, DC: American Psychological Association.

Belinskaya, E. P. (1999). Vremennye aspekty Ya-kontseptsii i identichnosti [Temporal aspects of selfconcept and identity]. Mir Psikhologii, 3, 40-46.

Bolkan, C., \& Hooker, K. (2012). Self-regulation and social cognition in adulthood: The gyroscope of personality. In S. K. Whitbourne \& M. J. Sliwinski (Eds.), The Wiley-Blackwell handbook of adulthood and aging (pp. 357-380). West Sussex: Blackwell Publishing Ltd.

Cross, S., \& Markus, H. (1994). Self-schemas, possible selves, and competent performance. Journal of Educational Psychology, 86(3), 423-438. doi:10.1037/0022-0663.86.3.423 
Dorfman, L. Ya. (2004). Ya-kontseptsiya: Differentsiatsiya i integratsiya [Self-concept: Differentiation and integration]. In L. Ya. Dorfman (Ed.), Integral'naya individual'nost', Ya-kontseptsiya, lichnost' [The integrated identity, self-concept, personality] (pp. 96-123). Moscow: Smysl.

Dunkel, C., Kelts, D., \& Coon, B. (2006). Possible selves as mechanisms of change in therapy. In C. Dunkel \& J. Kerpelman (Eds.), Possible selves: theory, research and application (pp. 187-204). New York, NY: Nova Science Publishers Inc.

Epshtein, M. N. (2001). Filosofiya vozmozhnogo: Modal'nosti v myshlenii i kul'ture [The philosophy of the possible: The modalities of thinking and culture]. Saint Petersburg: Aleteiya.

Erikson, M. (2007). The meaning of the future: Toward a more specific definition of possible selves. Review of General Psychology, 11(4), 348-358. doi:10.1037/1089-2680.11.4.348

Hoyle, R., \& Sherrill, M. (2006). Future orientation in the self-system: Possible selves, self-regulation, and behavior. Journal of Personality: Journal Compilation, 74(6), 1673-1696.

Kon, I. S. (1984). V poiskakh sebya: Lichnost' i ee samosoznanie [In search of the self: Personality and its identity]. Moscow: Politizdat.

Leontiev, D. A. (2011a). New reference points for understanding personality in psychology: From the necessary towards the possible. Voprosy Psikhologii, 1, 3-27.

Leontiev, D. A. (2011b). Podkhod cherez razvitie ego: Urovnevaya teoriya Dzh. Lyovindzher [The approach of ego development: Loevinger's stage theory]. In D. A. Leontiev (Ed.), Lichnostnyi potentsial: Struktura i diagnostika [Personality potential: Structure and diagnostics] (pp. 59-78). Moscow: Smysl.

Leontiev, D. A. (2014). Konets immanentnosti i perspektiva vozmozhnogo [End of immanence and the prospect of possible]. In G. L. Belkina (Ed.), Mesto i rol' gumanizma v budushchei tsivilizatsii [The place and role of humanism in the future of civilization] (pp. 174-185). Moscow: Lenand.

Markus, H., \& Nurius, P. (1986). Possible selves. American Psychologist, 41(9), 954-969. doi:10.1037/0003-066X.41.9.954

Oyserman, D., \& Markus, H. (1990). Possible selves and delinquency. Journal of Personality and Social Psychology, 59(1), 112-125.

Petrovsky, V. A. (2014). Self: The configuration of artifact. Kul'turno-istoricheskaia Psikhologiia, 10(1), $63-78$.

Pizzolato, J. E. (2007). Impossible selves: Investigating students' persistence decisions when their career-possible selves border on impossible. Journal of Career Development, 33(3), 201-223. doi:10.1177/0894845306296644

Ryff, C. D. (1991). Possible selves in adulthood and old age: A tale of shifting horizons. Psychology and Aging, 6(2), 286-295. doi:10.1037/0882-7974.6.2.286

Tkhostov, A. Sh. (1994). Topologiya sub»ekta (Opyt fenomenologicheskogo issledovaniya) [The topology of the subject (Attempt of a phenomenological study)]. Vestnik Moskozskogo Universiteta. Seriya 14. Psikhologiya, 2, 3-13.

Vasily Yu. Kostenko - junior research fellow, International laboratory of positive psychology of personality and motivation, National Research University Higher School of Economics. E-mail: vasily.kostenko@gmail.com 